\title{
Caminhos teórico-metodológicos para a análise da burocracia de nível de rua
}

Theoretical and methodological approaches for analyzing street-level bureaucracy

\section{Introdução}

O ciclo de políticas é um dos modelos explicativos dentro do campo das políticas públicas. Esse compreende as políticas como um ciclo deliberativo composto por diversos estágios e caracterizado por um dinâmico processo de aprendizado. Ele supõe que a ação pública se divide em etapas do processo político-administrativo subjacentes à resolução de problemas, sendo elas: definição de agenda, identificação de alternativas, avaliação das opções, seleção das opções, implementação e avaliação. É importante ressaltar que este ciclo não necessariamente condiz com a realidade, na medida em que muitas vezes os limites entre as etapas se confundem ou, ainda, as fases não seguem exatamente essa ordem cíclica. No entanto, tal referencial é um instrumento analítico útil para pensar os processos decisórios concernentes às políticas públicas (SOUZA, 2006).

Dentro do ciclo, a fase da implementação é aquela em que regras, rotinas e processos sociais são transformados em ações. Até este momento, a política apresenta-se de forma discursiva. Somente

Doutora em ciência política pela Universidade de Salamanca. Pesquisadora do Programa de Pós-graduação em Ciência Política da Universidade de Brasília, Brasília, DF, Brasil. E-mail: $<$ michelle.fernandez@unb.br>

2 Mestre em Ciência Política pela Universidade Federal de Pernambuco, Recife, PE, Brasil. E-mail: $<$ natalia.c.guimaraes@gmail.com> 
a partir da implementação as intenções políticas se transformam em fatos concretos, em realidade palpável. É na implementação que se verifica se aquilo que foi pensado nas fases anteriores vai se tornar realidade. Nesta fase, as dificuldades práticas para a resolução de problemas político-sociais aparecem. Porém, é importante ter claro que na implementação é possível deparar com mais do que problemas técnicos ou administrativos. Há, na verdade, grandes chances de que se encontre um emaranhado de elementos políticos que, por serem passíveis de modificação, podem frustrar ou readequar os planejamentos previamente estabelecidos (PRESSMAN; WILDAVSKY, 1973; WITTROCK; DELEON, 1986).

Diante do desenvolvimento do campo de análise de implementação de políticas públicas, instituições e atores adquirem centralidade e os burocratas se tornaram atores-chave para compreender os rumos das decisões e suas consequências em termos de resultados das políticas (LOTTA; SANTIAGO, 2017). Em consonância com esses avanços, no Brasil, vem aumentando o número de autores que se dedicam a analisar a implementação das políticas e a burocracia de nível de rua dentro do processo de implementação de políticas públicas.

Nessa perspectiva, este artigo pretende propor estratégias de análise do papel dos burocratas de nível de rua na implementação das políticas públicas. Para isso, e depois de retomarmos a discussão clássica sobre implementação a partir de diferentes gerações e a discussão teórica sobre a burocracia de nível de rua, apresentaremos dois possíveis caminhos metodológicos de incorporação da análise da burocracia de nível de rua nos estudos sobre implementação de políticas públicas.

\section{As diferentes abordagens analíticas da implementação de políticas públicas}

A implementação é a etapa do ciclo das políticas públicas na qual as políticas já formuladas são colocadas em prática. Este seria um processo complexo envolvendo pessoas, vontades, necessidades, poder, recursos, disputas, conhecimentos e desconhecimentos. 
Assim, fatores diversos levam a formas de implementação diferentes. Desde os estudos pioneiros, constata-se que as leis e decisões políticas não são executadas tal como concebidas, isto é, de forma direta, mecânica e automática (PRESSMAN; WILDAVSKY, 1973). Em vez disso, os processos de implementação são compreendidos como momentos de criação e transformação. Para Hill e Hupe (2014), tais procedimentos e interações não ocorrem de forma neutra e influenciam a produção de políticas públicas, na medida em que repercutem no seu conteúdo e nos seus resultados.

O crescimento dos estudos sobre implementação ocorreu nos anos 1970, quando se passou a dedicar especial atenção à atividade governamental, aumentando a preocupação com a efetividade das políticas públicas (BARRETT, 2004). Paulatinamente, as análises passaram a atentar não somente para os resultados das políticas, mas foram além, buscando compreender as discrepâncias entre o que fora formulado e o efetivamente implementado. Assim, ganhou relevância na análise de políticas públicas o processo de tradução das políticas para a ação propriamente dita, o que envolve interação e negociação entre aqueles que pretendem colocar a política em funcionamento e aqueles dos quais a ação depende.

Há quatro gerações de estudos sobre implementação de políticas públicas. A evolução histórica da literatura se baseia em dois modelos analíticos principais, top-down (de cima para baixo) e bottom-up (de baixo para cima), e nas diferentes tentativas de combiná-los. Os estudos seminais de Pressman e Wildavsky (1973) e Bardach (1977) inauguram essas análises. A partir de estudos de caso exploratórios e indutivos tinha-se como objetivo a produção de teoria relativa à implementação de políticas. Tais estudos tinham um forte componente normativo, tomando como base o ideal democrático de funcionamento do Estado oriundo da tradição weberiana.

O modelo top-down supõe uma rigidez na separação entre as etapas da formulação e implementação, o que conformaria uma hierarquia dos que estão no topo - os formuladores - sobre os que estão na base - os implementadores. Assim, os problemas da 
implementação seriam identificados como problemas de controle e de coordenação (PRESSMAN; WILDAVSKY, 1973) e os impactos das ações dos implementadores nos produtos das políticas seriam pouco expressivos. O importante seria que a política pública tivesse uma teoria causal explicativa adequada e objetivos bem definidos. A implementação, portanto, não seria marcada por processos políticos e deliberativos, mas sim pela atividade técnica, operacional e de natureza executiva.

Este modelo se baseia na distinção proposta por Wilson (1887) entre política - esfera dos tomadores de decisão - e administração - lugar de atuação dos implementadores. Portanto, ele parte de premissas funcionalistas e tecnicistas de que elaborar e decidir sobre políticas públicas é tarefa da esfera política e que implementar é um esforço administrativo para colocar em prática as ações já estabelecidas.

A perspectiva top-down também se preocupa com os impactos da implementação na efetividade das políticas e, por isso, tem como objetivo encontrar os erros de implementação e corrigi-los. Este modelo de abordagem tem como princípios a importância hierárquica da autoridade, a distinção entre temas políticos e temas administrativos e a busca pelo princípio da eficiência (MENY; THOENIG, 1992). Há, assim, a valorização do controle do processo por parte do topo da hierarquia de modo a garantir que as políticas sejam o mais próximo possível do plano concebido inicialmente.

A segunda geração dos estudos sobre implementação surge enquanto alternativa ao modelo top-down; é a abordagem bottom-up. De acordo com essa abordagem, as políticas públicas são compostas por múltiplos processos e são atividades contínuas que exigem tomada de decisão constante. A implementação seria apenas uma parte desse processo e também exigiria decisões, na medida em que nem tudo é passível de ser previsto, controlado ou normatizado no momento da formulação. Segundo esta perspectiva, a análise de políticas públicas deve olhar as políticas "de baixo para cima", atentando para o que de fato ocorre no momento de implementação (DELEON, 1999). Ela destina especial interesse 
ao sistema de implementação no nível local, uma vez que é neste âmbito que o setor público encontra diretamente os cidadãos e as empresas (WINTER, 2010). A partir dessa perspectiva, a burocracia de nível de rua é o agente principal no processo de implementação, ou seja, desde o desenho da política, sua organização e consequente execução (BERMAN, 1978; HJERN, 1982; LIPSKY, 1980)

Pode-se afirmar que a abordagem bottom-up está preocupada em compreender a implementação focando no que de fato acontece, mediante descrição e análise dos processos complexos que lhes são inerentes e seus resultados. É importante salientar que o modelo "de baixo para cima" trata de reconhecer as limitações das decisões técnicas e políticas do nível político central, o que confere bastante influência à equipe de linha de frente na realização da política e na aplicação das leis. Por isso, trabalhadores de linha de frente são considerados tomadores de decisão cruciais para tal perspectiva. Eles seriam atores com potencial capacidade de auto-organização e de atuação de forma própria na implementação das políticas. Neste sentido, a implementação seria a continuação do jogo político advindo de etapas anteriores a essa no ciclo de políticas públicas (BARDACH, 1977).

Por muito tempo, a literatura sobre implementação concentrou energias nos debates entre essas duas correntes e praticamente não foram desenvolvidas pesquisas que dialogassem entre si. Somente a princípio dos anos 1990 são propostos modelos alternativos buscando sintetizar elementos de ambas abordagens e focando na dialética das relações entre ideias e ações das políticas públicas.

Goggin et al. (1990) propuseram uma terceira geração de estudos de implementação. Essa geração tem como preocupação central os modelos sintéticos de análise da implementação e representa uma tentativa de sair da contraposição entre formulação e implementação, considerando-as processos decisórios contínuos que envolvem as políticas e os seus resultados (BARRETT, 2004; SABATIER, 1988).

A polarização entre abordagens top-down e bottom-up experimentada nos anos 1970 e 1980 refletia diferenças conceituais e 
ideológicas sobre o papel do Estado e a necessidade de controle da coisa pública. Muitas vezes, essas abordagens negligenciavam a atuação do Estado por não conseguirem contemplá-la em suas diversas concepções. A partir daí, surgiu a necessidade de combinar elementos dos enquadramentos "de cima para baixo" e "de baixo para cima" em um único modelo de análise de implementação de políticas que, por sua vez, poderiam ajudar a fornecer-nos uma maneira mais rica e precisa na compreensão do processo de implementação (LESTER et al., 1987). Dessa forma, alguns estudos propuseram combinar perspectivas, variáveis e achados de ambas as abordagens (ELMORE, 1985; SABATIER, 1986). Porém, muitas características importantes da terceira geração de pesquisa não puderam ser implementadas (SAETREN, 2014).

Mais recentemente surge uma quarta geração de estudos sobre implementação. A produção dessa nova geração passa a estar disseminada em uma variedade de países e continentes. Marcada por diferentes modelos de análise, a quarta geração sofre maior influência de outros campos de estudos, em especial da sociologia (LOTTA, 2019; PIRES, 2019). Temáticas relacionadas aos novos modelos da ação estatal, que se complexificaram após processos de reformas do Estado, também caracterizam a atuação dessa geração (HILL; HUPE, 2003; LOTTA, 2019; SAETREN, 2014).

A ideia de governança, de instrumentos de ação pública, a relação entre atores estatais e não estatais, os novos arranjos institucionais, os processos multiníveis, sistemas de coordenação, capacidades estatais na implementação são alguns temas que passam a ganhar relevância nessa nova agenda (HILL; HUPE, 2003; SAETREN, 2014). Além disso, duas ênfases que se reforçam mutuamente passaram a aparecer na pesquisa de políticas públicas: o componente democrático e participativo das políticas e um movimento em direção a mais pesquisas desde uma perspectiva interpretativa (DELEON, 1999).

Em estudo recente, Lotta et al. (2018) demonstram que houve um deslocamento analítico nos estudos de implementação a partir dos anos 2000. Com uma nova pauta voltada a compreender de forma mais profunda e sistemática os processos de implementação 
e sua implicação em temáticas específicas, temos uma transição de análises baseadas na dicotomia entre os modelos top-down e bottom-up para análises mais gerencialistas. Alguns dos temas tratados nessa nova agenda são: desigualdade na implementação, accountability, transparência, discricionariedade e autonomia, representação burocrática. Outra característica importante dessa quarta geração de estudos é a aproximação com a literatura de burocracia de nível de rua. Muitas dessas análises agregam a perspectiva dos burocratas implementadores para entender como funcionam os processos decisórios da implementação (LOTTA et al., 2018).

Diante do desenvolvimento do campo de análise de implementação de políticas públicas, ao longo das suas gerações de estudos, instituições e atores adquirem centralidade e os burocratas tornam-se atores-chave para compreender os rumos das decisões de implementação e suas consequências em termos de resultados das políticas.

No Brasil, o avanço dos estudos sobre burocracia de nível de rua está inserido no crescimento do interesse pelos processos de implementação. Na primeira década dos anos 2000 começam a aparecer estudos mais sistemáticos sobre a implementação de políticas em temáticas como capacidades estatais, arranjos institucionais, instrumentos de implementação, burocracia, organizações de nível de rua, entre outros. Assim, apresenta-se, a seguir, alguns dos estudos sobre implementação e burocracia implementadora no contexto brasileiro. Sem a pretensão de mapear toda a produção nacional, trata-se de trazer exemplos das linhas que já são produzidas no contexto nacional.

Assim, Lotta (2010) investiga a atuação dos agentes comunitários de saúde no Programa Saúde da Família, com uma particular inserção comunitária. A autora aborda os elementos centrais às práticas realizadas pelos burocratas e os estilos de interação que estabelecem com os usuários. Oliveira (2012), por sua vez, analisa algumas características da organização policial e as falas de oficiais da polícia militar da Bahia para ilustrar as dificuldades no controle dos burocratas que estão na ponta do sistema. Lima e D’Ascenzi 
(2017), a partir de uma análise qualitativa, buscam apreender a influência da discricionariedade da burocracia de rua na Política Nacional de Humanização nas unidades básicas de saúde de Porto Alegre. Cordeiro (2018), mediante entrevistas com educadoras sociais, investiga o papel delas na implementação da política para mulheres ameaçadas de morte em Pernambuco. Em um esforço de construção teórica, Bonelli et al. (2019) analisam as múltiplas dimensões da atuação dos burocratas de nível de rua no Brasil e, a partir daí, apresentam três diferentes perspectivas analíticas sobre a atuação desses burocratas.

As próximas seções apresentarão a discussão sobre os burocratas de nível de rua e a discricionariedade desses burocratas enquanto categoria de análise no processo de implementação das políticas públicas.

\section{Os burocratas de nível de rua como atores políticos}

Uma política pública possui dois elementos básicos: intencionalidade pública e resposta a um problema público. Quando falamos de políticas públicas, estamos fazendo referência ao conteúdo concreto e ao conteúdo simbólico de decisões políticas. Estamos, também, levando em consideração o processo de construção e atuação dessas decisões. Portanto, o processo de construção das políticas públicas está intimamente vinculado com a atuação dos atores políticos.

Alguns elementos básicos inerentes à análise de implementação de políticas são pessoas e organizações, com seus interesses, competências e comportamentos variados (SECCHI, 2010). Assim sendo, as políticas públicas são estabelecidas por um emaranhado de atores e de interações entre eles. São considerados atores todos aqueles indivíduos, grupos ou organizações que desempenham um papel na arena política. Eles influenciam o processo político e possuem comportamento e interesses que variam conforme os papéis que interpretam no cenário político.

Moon e Ingraham (1998), em seu estudo sobre reformas administrativas, apresentam os atores políticos divididos em três categorias: os políticos - aqueles que são eleitos e os designados politicamente 
por estes; a sociedade civil - grupos que se posicionam politicamente, mas são externos à administração pública; e os burocratas - aqueles selecionados por concurso público ou por seleção pública.

Weber (1947), um dos primeiros estudiosos sistemáticos da burocracia, colocou os burocratas no centro da sua discussão sobre poder racional-legal. Para ele, este ator político cumpriria o papel de executar de forma fidedigna as normas e regras estabelecidas pelo Estado, de acordo com os procedimentos preestabelecidos e garantindo a manutenção das hierarquias e de suas atribuições. Portanto, o papel do burocrata dentro da estrutura organizacional do Estado é de obedecer aos políticos eleitos e seguir, literalmente, as normas legais estabelecidas. Porém, a complexificação das sociedades e a consequente modernização da estrutura e da atuação do Estado ressignificou o papel dos burocratas, dando lugar à percepção de novos arranjos, de outras funções e de uma diversidade de divisões de atribuições (LOTTA, 2012).

Dito isso, pode-se afirmar que a burocracia forma o corpo dos funcionários públicos e possui características específicas que afetam o processo das políticas públicas, como a estabilidade de emprego, a seleção e promoção baseadas em competências técnicas e experiência. $\mathrm{O}$ corpo burocrático tem como função manter a administração pública funcionando, sem depender diretamente dos ciclos eleitorais (SECCHI, 2010). A importância de estudar os burocratas está no fato de que a neutralidade na implementação das políticas públicas, levantada a priori por Weber (1947), não se confirma na prática. Portanto, é importante entender a atuação desses atores para entender a própria implementação das políticas.

Segundo Lotta et al. (2018), existem diferentes tipos e escalões da burocracia, quais sejam o alto e o médio escalões, e a burocracia de nível de rua. Tal diferenciação reflete o esforço de pensar a burocracia a partir de sua segmentação vertical, analisando a forma como os atores posicionados nos diferentes níveis do aparato estatal se relacionam com os processos técnico-políticos e desenvolvem modos de influência e intervenção distintos ao longo processo de construção e operação das políticas públicas. 
Nesse sentido, a burocracia de alto escalão diz respeito à elite administrativa mobilizada para a ocupação de cargos de nível estratégico. Ela atua na mediação da interação entre os níveis operacionais e os políticos eleitos (ALESSIO; AMBROZIO, 2016). A burocracia de médio escalão, por sua vez, corresponde aos atores que desempenham funções de gestão e direção intermediária nas burocracias - são os gerentes, diretores, coordenadores, supervisores. Mediam, portanto a relação entre a elite administrativa e os operadores das políticas públicas (LOTTA et al., 2014).

Por fim, há a burocracia de nível de rua, street level bureaucrats, termo cunhado por Lipsky (1980) que corresponde à estrutura burocrática da administração pública que trabalha no contato direto com os cidadãos. Tal burocracia é composta pelos profissionais que lidam diretamente com os beneficiários de uma determinada política, atuando como elo entre Estado e sociedade, e que contam com substancial grau de discricionariedade para exercício de suas funções. Compõem esta categoria, por exemplo, policiais, professores, médicos e funcionários de atendimento ao público em geral. É a esta categoria que a presente análise se atém.

Para Lipsky (1980), os burocratas de nível de rua podem ser considerados os "verdadeiros formuladores" das políticas, uma vez que elas também são feitas pelos responsáveis por sua implementação: as decisões dos burocratas, suas rotinas e as formas como lidam com as pressões e incertezas do dia a dia são o que de fato caracteriza as políticas públicas. Esta abordagem da implementação de políticas públicas parte dos comportamentos dos atores concretamente onde existe o problema público. Implementadores teriam, assim, mais participação nas propostas de solução dos problemas durante a implementação.

Neste modelo, o formato da política pública após as fases de formulação e tomada de decisão pode não ser definitivo. Isso permitiria a modificação da política pelos implementadores de acordo com as especificidades de cada lugar onde ela está sendo implementada. Esse papel de modificador exercido pelo implementador pode 
ser entendido como uma necessidade de quem se depara com os problemas práticos da implementação.

$\mathrm{Na}$ medida em que é responsável por distribuir benefícios e sanções, a burocracia de nível de rua protagoniza controvérsias políticas relevantes no que diz respeito à prestação de serviços públicos (LIPSKY, 1980). Primeiramente porque a discussão sobre o alcance e os limites das políticas públicas é, na verdade, uma discussão sobre o alcance e os limites das funções desempenhadas pelos burocratas de nível de rua. Em segundo lugar, porque as controvérsias estariam relacionadas ao considerável impacto da atuação desses profissionais na vida dos cidadãos. São os burocratas de rua quem na prática selecionam quais cidadãos serão beneficiados ou sancionados pelas políticas, são eles quem explicitam quais serviços públicos estão disponíveis para a população, eles quem prestam os serviços ao público-alvo das políticas, entre outras atividades que faz com que atuem como lócus da ação estatal.

A entrega dos serviços pelos burocratas de nível de rua à população se dá de forma imediata e pessoal. Isso faz com que esses tenham de lidar diretamente com a reação do público às suas decisões, bem como com as implicações das mesmas. Ao dizer isto, Lipsky (1980) sugere que a sociedade reage às políticas públicas e problematiza que, para os cidadãos, uma coisa é ser tratado com indiferença e pouca empatia por profissionais com quem não lidam diretamente e, portanto, não conhecem suas demandas e necessidades específicas; outra coisa, é ser tratado de tal modo por aqueles com quem lidam diretamente e dos quais esperam, no mínimo, uma escuta atenciosa. Como consequência, a realidade de trabalho dos burocratas de rua dificilmente poderia estar mais distante do ideal da impessoalidade e de desvinculação esperado para o momento de tomada de decisão.

Nesse sentido, Maynard-Moody e Musheno (2000, 2012, 2015) desenvolvem diversos estudos nos quais analisam empiricamente a atuação de burocratas de nível de rua em áreas variadas, especialmente nas de educação, segurança e assistência social. A partir deles, os autores propõem uma perspectiva de análise que considera 
como os próprios agentes de nível de rua percebem sua atuação. Fazendo uso de observações participantes, etnografias e histórias, os autores afirmam que tais burocratas tomam suas decisões caso a caso, ou seja, eles mobilizam valores morais, fazem julgamentos, se baseiam nas relações estabelecidas com os usuários das políticas e com seus pares para pensar como agir em cada situação.

Ao mesmo tempo que os burocratas de rua têm de lidar tão diretamente com os usuários das políticas, eles também precisam adotar padrões e categorias sociais para identificar e alocar os cidadãos de maneira mais ou menos clara e, assim, atender suas demandas (LIPSKY, 1980). Ou seja, mesmo que os cidadãos acessem os serviços enquanto pessoas individualizadas e portadoras de diferentes experiências, personalidades e necessidades, o atendimento deles pela burocracia requer, em alguma medida, a adoção de padrões unificados e indiferenciados. Assim, os clientes tendem a experimentar suas necessidades como problemas individuais e suas demandas como expressões individuais de uma expectativa, esperando, portanto, tratamentos individuais para aquelas questões. Já os burocratas de rua experimentam os problemas dos clientes como categorias de ação e suas demandas individuais como componentes de agregação (LOTTA, 2010).

Nesse sentido, a busca por um equilíbrio entre um atendimento individualizado, sensível às especificidades dos cidadãos, por um lado, e um atendimento imparcial, fiel à aplicação das regras, por outro, representa uma questão central para os agentes implementadores de políticas públicas (BERGEN; WHILE, 2004). Para Maynard-Moody e Musheno (2012) a "improvisação pragmática" seria uma estratégia adotada pelos burocratas de linha de frente para lidarem com essas questões.

Outra questão relevante relativa à atuação da burocracia de nível de rua é o fato de que seus clientes não são voluntários (LIPSKY, 1980; OLIVEIRA, 2012). Isto é, são indivíduos que acessam aqueles serviços por não terem outra opção, na medida em que os serviços prestados pelas políticas públicas ou são monopolizados pelo Estado ou são muito caros para serem acessados pela via privada pela 
maioria da população. Diante disso, os cidadãos dependem da ação dos agentes de nível de rua para acessarem os recursos e serviços, o que para Maynard-Moody e Musheno (2000) faz da relação entre a população e tais burocratas desigual - ainda que marcada pela pessoalidade e proximidade.

Com relação às condições de trabalho com as quais a burocracia de nível de rua tem de lidar, Lipsky (1980) fala da crônica inadequação dos recursos públicos disponíveis para as tarefas a serem desempenhadas pelos burocratas de rua. Ao dizer isso, o autor sugere que a prestação de serviços públicos implica num imenso volume de trabalho sob a responsabilidade dos burocratas de rua, ao passo que conta com uma quantidade limitada de recursos para dar conta dele. Essa situação imprime um clima de pressão à atuação desses profissionais. A escassez acarreta, portanto, na necessidade de simplificações no exercício das tarefas e criação de rotinas que permitam dar conta das mesmas. Por isso, comumente, a burocracia de rua é criticada por sua incapacidade de prestar serviços de forma satisfatória.

Uma outra questão tem a ver com a relação entre a oferta e a demanda das políticas públicas. A demanda pelas políticas cresce para alcançar a oferta. Em outras palavras, quanto mais serviços/ benefícios são disponibilizados pelas agências responsáveis pelas políticas públicas, maior é a demanda ${ }^{3}$ por eles. Essa situação se agrava uma vez que a demanda por políticas públicas aumenta ao longo do tempo, tanto do ponto de vista quantitativo quanto do ponto de vista qualitativo. Diante disso, muitas vezes, a burocracia de nível de rua fica presa em um ciclo de mediocridade, ou seja, quanto melhor o programa, maior a demanda pelo serviço, o que, por sua vez, força a agência responsável pela política a limitar o serviço artificialmente ou a impor custos aos clientes para acessá-lo.

3 O conceito de demanda nos serviços públicos diz respeito não somente a parte de uma transação entre cidadãos e governo, mas também a um conceito transacional. Não requer apenas um requerente, mas também um fornecedor mais ou menos encorajador. Em termos mais concretos, a demanda por serviços pode ser estimada, mas não pode ser fielmente conhecida. É uma função não apenas das expressões das preferências dos clientes, mas também dos esforços do governo para oferecer serviços e registrar ou reconhecer as respostas dos clientes (LIPSKY, 1980). 
Outra questão central é que, em geral, os objetivos dos serviços públicos são vagos, conflitantes, ambíguos e, muitas vezes, representam horizontes desejáveis e não alvos fixos (BERGEN; WHILE, 2004; LIPSKY, 1980). Tais características refletem os conflitos experimentados no momento da formulação e que não foram superados, sendo levados para a etapa seguinte do ciclo das políticas públicas. Além disso, a falta de clareza dos objetivos das políticas relaciona-se com a dificuldade de saber quais os instrumentos e mecanismos que funcionam na prática para lidar com o problema a ser enfrentado pela política em questão.

Essa imprecisão na definição dos objetivos das políticas públicas dificulta a mensuração da atuação da burocracia de rua, o que leva as agências responsáveis pelas políticas a, comumente, incorrerem em definições de performance bastante politizadas. Isso é especialmente relevante ao se considerar que a maior parte das tarefas a serem realizadas pelos burocratas de rua diz respeito à prestação de serviços e à tomada de decisões - atividades extremamente difíceis de serem supervisionadas e submetidas ao escrutínio crítico. Ainda com relação à abrangência dos objetivos das políticas, seria necessário levar uma série de fatores em consideração para uma mensuração adequada da atividade da burocracia de nível de rua.

Os burocratas de rua atuam ainda transformando o conceito de matéria-prima, no caso os usuários das políticas, tornando mais legítima a discrepância entre os recursos disponíveis e os objetivos atingidos (LIPSKY, 1980). Dessa forma, os agentes de nível de rua ensinam aos clientes o papel de ser um cliente, repassando os procedimentos e a forma como devem se comportar, assim como o grau de deferência esperado, as penalidades possíveis, o que esperar dos burocratas e como adquirir informações (AUYERO, 2012; LOTTA, 2010).

A burocracia de nível de rua desenvolve formas de lidar com as incertezas do seu trabalho, seja criando padrões de práticas que limitem a demanda, maximizem o uso dos recursos disponíveis e assegurem a conformidade dos clientes; seja pela modificação do conceito de seu trabalho, restringindo seus objetivos e, com isso, 
diminuindo a discrepância entre os recursos disponíveis e objetivos atingidos. Assim, a despeito dessas dificuldades, a burocracia baseia-se em algumas referências para exercer suas funções, de modo que seu comportamento está fortemente estruturado pelo conjunto de incentivos e sanções que incidem sobre ela.

Sobre isso, Ferreira e Medeiros (2016), ao revisarem a literatura sobre implementação de políticas públicas, sistematizam três conjuntos de fatores que afetam o comportamento dos burocratas de linha de frente: os fatores pessoais, os fatores institucionais/ gerenciais e os fatores relacionais. Neles estão contidas discussões sobre a questão da discricionariedade, ponto em torno do qual ainda orbitam muitas controvérsias relativas aos limites e potencialidades de seu uso; discussões relativas às interações dos burocratas de nível de rua com o público da política, pensando os desafios de melhorar a qualidade das políticas e as oportunidades que podem surgir com o envolvimento da comunidade; discussões referentes à relação de tais burocratas com o sistema de gestão, que para os autores acaba sendo pouco influente nos contextos de implementação; discussões sobre accountability, uma vez que entre o interesse geral da política e as necessidades específicas dos cidadãos estão os burocratas dotados de discricionariedade; discussões sobre o autointeresse, com novas teorias sendo mobilizadas para pensar a questão; e, por fim, discussões sobre as normas/regras/crenças/ valores que incidem sobre a atuação de tais burocratas.

A partir desse prisma analítico, Bonelli et al. (2019) propõem uma visão dialética e integradora de três perspectivas propostas fundamentais para análise - estrutural, de ação individual e relacional. Os autores supõem que a aderência a regras e estruturas estabelecidas, a ação individual dos burocratas de nível de rua e suas interações afetam de forma conjunta a implementação de políticas públicas. Portanto, propondo a compatibilidade e a integração de três diferentes abordagens em um único construto teórico, os autores trazem a discussão da atuação desses burocratas da teoria para o campo empírico, constatando que, no dia a dia, todos esses fatores coexistem simultaneamente. 
$\mathrm{Na}$ medida em que os burocratas de nível de rua desempenham funções muito relevantes e atuam com relativo grau de autonomia, a forma como trabalham e estabelecem suas interações influencia na implementação das políticas públicas. Portanto, a burocracia não é apenas o conjunto dos funcionários públicos e dos processos administrativos. É também um dos fundamentos do exercício do poder estatal e do governo democrático e, por isso, é necessária a compreensão da sua composição, seu funcionamento e sua relação com os dirigentes políticos eleitos (MAY; WINTER, 2007; OLIVIERI, 2011).

A partir das diferentes abordagens do papel e da atuação dos burocratas de nível de rua, a seção seguinte discutirá, de maneira mais detida, a discricionariedade subjacente à atuação desses atores, uma vez que esta é uma dimensão fundamental para as análises de implementação que dão centralidade a esses agentes.

\section{A discricionariedade no nível de rua como categoria de análise}

A discussão apresentada evidencia que, ao passo que os burocratas de rua desenvolvem suas funções inseridos numa estrutura institucional e programática - seguindo normas, protocolos e regras e situados numa hierarquia e sistema gerencial -, eles também têm o poder de implementar as políticas públicas de forma própria, uma vez que há uma série de brechas nessas estruturas que lhes possibilita agir com substancial grau de discricionariedade. É à discussão deste conceito que esta seção se dedica.

A despeito das críticas realizadas por alguns autores à ênfase no papel dos burocratas, por considerarem-na negligente com questões fundamentais, como o fato de que nas democracias o controle sobre as políticas deve ser feito pelos representantes eleitos e o poder dos agentes implementadores não se assenta nessa base (MATLAND, 1995), é hegemônico o entendimento de que a discricionariedade é uma realidade no desenvolvimento das políticas públicas. Assim como o fato de que seu exercício interfere na implementação das 
políticas à revelia das concepções de seus formuladores e dos grupos que lhes deram apoio. (LIMA; D’ASCENZI, 2013).

Lipsky (1980) argumenta que o exercício da discricionariedade pelos burocratas de rua não quer dizer que eles não estejam sujeitos a regras, regulamentos e diretrizes superiores ou a normas e práticas de seu grupo ocupacional; pelo contrário, as categorias de elegibilidade, a natureza das regras, os regulamentos e serviços são moldados por elites políticas e são as principais referências para atuação desses burocratas. Além disso, na medida em que os burocratas de nível de rua são profissionais, é razoável supor que exerçam considerável discricionariedade, pois é essa a atitude esperada dos profissionais em geral diante de decisões concernentes ao seu campo de atuação.

O que não é tão razoável supor, e que é justamente uma das inovações trazida por Lipsky (1980), é que as regras podem, na realidade, atuar como impeditivos para a boa implementação das políticas. Isto porque elas podem ser volumosas e contraditórias a ponto de sua aplicação só ser viável de modo seletivo. Além disso, comumente, os regulamentos dos programas e políticas passam por constantes alterações, inviabilizando a aderência a qualquer norma, exceto aos preceitos básicos e fundamentais de elegibilidade. Seria possível argumentar que uma melhor elaboração das regras reduziria a discricionariedade dos burocratas, garantindo uma prestação de serviço mais uniforme e padronizada. No entanto, em geral, os burocratas de nível de rua desempenham funções complexas para as quais mesmo uma melhor elaboração de regras, diretrizes ou instruções não poderia circunscrever as alternativas para todas as situações com as quais lidam no cotidiano da política.

Com relação à autonomia da burocracia de rua em relação à autoridade organizacional, Lipsky (1980) afirma que muitas vezes os burocratas de nível rua não compartilham das perspectivas e preferências daqueles que formulam as políticas, de modo que não consideram legítimas as ordens "vindas de cima”. Assim, é possível que, ao menos em alguns aspectos, não trabalhem em conformidade com os objetivos declarados em normas, regulamentos e diretrizes 
de uma determinada política. Isso se deve ao fato de que não raro os burocratas de rua são recrutados sem que tenham afinidade com o que é proposto pela política e/ou ao fato de os incentivos, ou sanções, disponíveis para constranger as ações dos burocratas não serem suficientes. Sobre isso, Ferreira e Medeiros (2016) dirão que os sistemas de gestão das políticas públicas tendem a ter baixa influência na atuação dos agentes de linha de frente, seja porque os gerentes costumam estar ausentes do cotidiano de implementação, seja porque há conflitos de interesses ou seja porque os burocratas se alienam com relação aos propósitos das políticas.

Autores como Ferreira e Medeiros (2016), Maynard-Moody e Musheno (2000, 2012, 2015) e Berk, Galvan e Hattam (2013) também têm, por perspectivas diversas, discutido a questão da discricionariedade. Alguns estudos apresentam as contradições dos processos relativos ao seu uso pelos burocratas de nível de rua. Ao revisarem o que vem sendo produzido pela literatura, Ferreira e Medeiros (2016) argumentam que, se por um lado há defensores de um maior controle da atuação discricionária e, por outro, há os que defendam as suas potencialidades, de maneira geral ainda faltam estudos que se debrucem sobre a gestão dos possíveis usos da discricionariedade.

Berk, Galvan e Hattam (2013), por sua vez, dialogam com essa discussão ao pensar as relações entre ordem, agência e mudança. Eles argumentam que as teorias existentes são insuficientes para pensar as mudanças institucionais e que, embora as regras, os papéis institucionais, a trajetória e a cultura situem os atores nos contextos políticos, é a ação humana a matéria-prima para improvisação e transformação política. A essa agência, os autores chamam de criatividade política.

Nesse sentido, Maynard-Moody e Musheno (2000, 2012, 2015) afirmam que comumente as investigações sobre burocratas de nível de rua estão centradas em pensar formas de garantir que estes executem fielmente as políticas, em relação à sua concepção original, considerando que há variação entre elas. Esta seria a perspectiva estado agente e, embora seja fundante e fundamental para 
as análises sobre burocracia de nível de rua, ela não é exclusiva, argumentam. Assim, os autores propõem uma perspectiva alternativa - à qual chamam de cidadão agente - na qual a discricionariedade seja pensada como uma manifestação da agência dos burocratas, uma vez que suas decisões são baseadas em questões que vão além das regras, normas e procedimentos. A agência seria, portanto, uma dimensão inerente à ação humana, que se manifesta nas estruturas sociais, não sendo distribuída igualmente na sociedade, tendo assim, caráter profundamente interacional. Ela seria, portanto, uma habilidade de fazer julgamentos e agir a partir deles diante das situações.

A discussão apresentada evidencia que a discricionariedade pode ser vista como um ponto positivo para a atividade implementadora, ao viabilizar uma atuação ponderada por parte da burocracia diante de situações que exigem respostas às dimensões humanas (LIPSKY, 1980). É ela que permite aos burocratas observar cada situação e executar julgamentos sensíveis diante delas, não as reduzindo a formatos programados. Para Elmore (1979), a discricionariedade seria, portanto, um mecanismo adaptativo derivado do conhecimento, das habilidades e da proximidade que os burocratas de rua têm com relação às tarefas essenciais desempenhadas pela organização de uma determinada política.

Além disso, a discricionariedade dos burocratas de nível de rua dá margem para que os cidadãos nutram a expectativa de que eles responderão favoravelmente às suas demandas, uma vez que supostamente têm obrigação geral e difusa para com o "interesse público". Assim, em um mundo de agências grandes e impessoais que aparentemente detêm as chaves de importantes benefícios, sanções e oportunidades, a imprecisão quanto à atuação dos burocratas de nível de rua dá lastro à esperança dos cidadãos com relação a decisões favoráveis por parte de tais agentes. Nesse sentido, a busca pelo equilíbrio entre compaixão e flexibilidade, por um lado, e imparcialidade e aplicação rígida de regras, por outro lado, representa uma grande questão para o serviço público. 
A discussão realizada até aqui reforça a questão crucial de que a implementação é a formulação em construção, na medida em que os encaminhamentos derivados das decisões discricionárias dos burocratas de rua são efetivados e acabam tornando-se as políticas propriamente ditas. Isto porque esses burocratas, por meio de suas decisões, acabam alterando objetivos traçados no processo de formulação das políticas que serão entregues ao público-alvo, seja porque os objetivos são planejados de forma equivocada - não dando conta da complexidade das situações com os quais terão de lidar; mal explicados -, dando margem a interpretações diversas por parte dos burocratas; seja por discordarem daquilo estabelecido como objetivo - e tendo condições de agirem com alguma autonomia diante disso.

Apesar do reconhecimento da importância da discricionariedade, além do próprio Lipsky (1980), autores como Meier e O’Toole (2006) apontaram conflitos dela decorrentes, seja no que diz respeito à interação dos burocratas de rua com cidadãos, seja no tocante à interação deles com outros funcionários do poder público. Com relação aos cidadãos, a discricionariedade também sinaliza a existência de conflitos na medida em que a prática profissional desses atores interfere diretamente na trajetória das pessoas, influenciando suas chances e oportunidades de vida. Isso, por sua vez, repercute na forma como a atuação dos agentes públicos é recebida pelos cidadãos (LIPSKY, 1980).

Ainda no que tange aos cidadãos, há o fato de que os clientes dos burocratas de rua sejam clientes não voluntários, como já discutido anteriormente. Clientes não voluntários não têm condições de disciplinar os burocratas que geralmente não têm nada a perder por falhar com eles. Se a demanda é inesgotável, o fato de os clientes ficarem insatisfeitos significa apenas que outros estarão na fila para tomar seu lugar. Assim, a perda de clientes não é determinante do comportamento dos burocratas de nível de rua.

Nesse sentido, um dos riscos apontados é a possível arbitrariedade de certos burocratas quanto ao uso do poder, tanto na imposição de tratamentos negligentes, como no que se refere a 
abuso pessoal ou disciplinar (LIPSKY, 1980). A atuação dos burocratas de nível de rua está, portanto, intimamente ligada à produção e reprodução de desigualdades sociais (MAYNARD-MOODY; MUSHENO, 2012; PIRES, 2019). Isto porque a sua atuação não é um processo neutro, mas atravessado por julgamentos baseados em valores e crenças (BERGEN; WHILE, 2004; MAYNARD-MOODY; MUSHENO, 2003).

Por outro lado, os próprios agentes de rua dependem desses cidadãos para legitimarem e apoiarem suas ações perante o público, na medida em que os clientes têm um estoque de recursos que podem facilitar ou dificultar as tarefas dos agentes públicos (LIPSKY, 1980). Essas interações com os usuários, portanto, apresentam-se tanto como um desafio para melhoria da qualidade das políticas quanto como uma oportunidade para envolvimento da comunidade nos processos de implementação (FERREIRA; MEDEIROS, 2016).

Já na relação com os administradores, os conflitos existentes dão-se na diferença de objetivos e valores envolvidos na função: enquanto estes pretendem alcançar os resultados consistentes com os objetivos da agência, os burocratas de rua querem processar o trabalho em consonância com suas próprias preferências, assegurando o que for necessário para completarem suas obrigações. Como decorrência, a relação entre ambos, embora conflituosa, é de mútua dependência.

Uma parte da literatura que estuda a discricionariedade também aponta uma discussão no que toca aos processos de accountability ou controle das ações desempenhadas pelas burocracias de rua (HUPE; HILL, 2007). O controle democrático dos agentes implementadores é considerado uma preocupação constante no processo de implementação de políticas pelas administrações públicas (MEYERS; VORSANGER, 2010; FERREIRA; MEDEIROS, 2016). Usando como pressuposto a associação entre os burocratas e valores não democráticos, ainda é difícil determinar o lugar da discricionariedade da burocracia em termos de governança democrática, ainda que se reconheça a contribuição da burocracia à governança (HUPE; EDWARDS, 2012; MEIER; O’TOOLE, 2006). 
No processo de implementação de políticas públicas, podemos deparar com a ausência de controle das ações dos burocratas que podem ser traduzidas no exercício da discricionariedade na realização de suas atividades laborais. Por isso, a atuação discricionária e o controle dos burocratas de nível de rua suscitam uma série de questões importantes e delicadas para estudiosos da etapa de implementação. É neste sentido que alguns estudos buscam avançar no entendimento da dinâmica de atuação dos burocratas de nível de rua (MAYNARD-MOODY; MUSHENO, 2000, 2012, 2015; FERREIRA; MEDEIROS, 2016). Além disso, entender o possível equilíbrio entre controle e discricionariedade nos permitiria propor modelos de coordenação associados à autonomia desses atores.

Diante de a toda discussão teórica realizada até aqui, relativa a questões como ciclo de políticas públicas, implementação de políticas públicas e suas gerações de estudos, os fundamentos da burocracia de nível de rua e a discricionariedade que lhe é característica, adentrar-se-á a seguir no tópico em que são feitos apontamentos teórico-metodológicos referentes às possibilidades de análise da burocracia de nível de rua.

\section{Diferentes caminhos teórico-metodológicos para analisar a burocracia de nível de rua}

Os burocratas de nível de rua são responsáveis por muitas atividades centrais dentro da máquina burocrática. Por ocupar lugar estratégico na interface entre cidadãos e Estado, esses atores têm oportunidades importantes para influenciar a execução de políticas públicas (MEYERS; VORSANGER, 2010). Portanto, há uma margem de atuação autônoma desses agentes públicos que chamamos de discricionariedade. Nos estudos sobre burocracia de nível de rua, temos a categoria "discricionariedade" como algo central na discussão do labor desses burocratas.

É possível, por um lado, discutir fatores que atuariam sobre a discrição dos burocratas de nível de rua e, por outro lado, é possível analisar fatores político-institucionais que são influenciados pela atuação discricionária desses atores. Portanto, nas linhas que 
seguem, serão apresentadas duas propostas diferentes para analisar a atuação da burocracia de nível de rua: a primeira, considerando essa uma variável dependente ${ }^{4}$, influenciada por outros fatores; e a segunda, considerando a mesma uma variável independente ${ }^{5}$, como fator influenciador de outros processos.

\section{O Burocrata de nível de rua como variável dependente}

Três conjuntos de fatores incidem na atuação dos burocratas de nível de rua: fatores políticos, fatores organizacionais e fatores profissionais. Os fatores políticos estão pautados dentro de um sistema de controle político exercido sobre os burocratas de nível de rua. Em estudos que analisam, principalmente, sistemas federalistas, discute-se a capacidade de controle que os funcionários políticos podem exercer sobre as ações dos burocratas de nível de rua. A atuação dos trabalhadores da ponta estaria vinculada ao poder de diretrizes de políticas. Estudos quantitativos, baseados em dados administrativos, mostraram que o poder político partidário explica a variação do desempenho dos trabalhadores da ponta (KEISER, 1999; KEISER; SOSS, 1998; MEYERS; VORSANGER, 2010). Por outro lado, estudos qualitativos, que analisam com mais proximidade a atuação dos burocratas de nível de rua, demonstraram uma menor capacidade dos funcionários políticos de controlar os trabalhadores da ponta (MEYERS; VORSANGER, 2010).

Um segundo conjunto de fatores que pode incidir sobre a atuação dos burocratas de nível de rua são os fatores organizacionais.

4 Variável que representa o fenômeno a ser explicado (King; Keohane; Verba, 1994). Diz respeito aos fatores explicados por serem influenciados ou determinados pela variável independente. É o elemento que surge, altera-se ou desaparece quando o investigador manipula a variável independente. Em outras palavras, a variável independente é o antecedente e a variável dependente é o consequente. Os cientistas procuram fazer previsões acerca do comportamento das variáveis dependentes com base no aspecto das variáveis independentes, e, de maneira inversa, podem desejar aclarar um determinado fato ou fenômeno - variável dependente -, por meio da identificação do acontecimento - variável independente - que o ocasionou (Lakatos; Marconi, 2003).

5 Variável que representa o fator causal de uma teoria (King; Keohane; Verba, 1994). É aquela que exerce influência sobre uma outra variável, determinando ou afetando o resultado observado na segunda com alguma precisão e regularidade. Comumente é manipulada pelo pesquisador em seus experimentos a fim de compreender a sua influência sobre o resultado do fenômeno em análise (Lakatos; Marconi, 2003). 
Estes focam no papel das organizações no controle - ou ausência dele - da discricionariedade dos trabalhadores da ponta, ou seja, a atuação dos profissionais pode estar vinculada à estrutura do ambiente de serviço (MEYERS; VORSANGER, 2010). A atuação do burocrata de nível de rua pode estar condicionada aos incentivos organizacionais formais, na medida em que a complexidade organizacional aumenta a necessidade de decisões discricionárias, bem como dificulta o monitoramento e supervisão de ações. Este ambiente complexo é típico de sistemas federados, em que a organização do próprio Estado denota uma complexa estrutura organizacional, seguida por um emaranhado de regras e normas que regem a implementação das políticas públicas, mas não limita a atuação dos seus implementadores, já que a existência de muitas regras leva à aplicação seletiva das mesmas pelos implementadores (MAYNARD-MOODY; MUSHENO, 2003; SIMON, 1983). Dentre os fatores organizacionais, há, também, evidências sobre a relação entre restrição de recursos e a direção discricionariedade dos trabalhadores de linha de frente. O manejo de recursos escassos, associado ao enfrentamento de alta demanda de usuários, pode levar a atitudes particularistas por parte dos implementadores de nível de rua ou à criação de uma mesma rotina para usuários com problemas diferentes (LIPSKY, 1980).

Por fim, temos os fatores profissionais, que podem ser traduzidos pela ideologia do trabalhador e das normas profissionais (MEYERS; VORSANGER, 2010). Estes fatores focam na influência dos interesses individuais do implementador e nas normas e processos profissionais que constroem significado nas rotinas de trabalho. Segundo Winter (2010), aspectos da ideologia do trabalhador podem ser importantes para determinar o rumo do comportamento discricionário destes. Este fator pode determinar uma conduta mais ou menos excludente com relação aos usuários que buscam ser atendidos por um determinado serviço, por exemplo. Além disso, o papel das normas próprias do serviço e das crenças coletivas dos trabalhadores podem figurar um incentivo contundente para o desempenho burocrático. Para ilustrar essa temática, 
apresentamos a discussão de Cordeiro (2018) que, ao analisar a atuação das educadoras sociais enquanto burocratas de nível de rua da política de abrigamento para mulheres ameaçadas de morte em Pernambuco, dedica especial atenção à compreensão que tais profissionais têm acerca da violência contra a mulher, bem como sobre impressão delas em relação às alternativas que o serviço propõe para as usuárias - tendo em vista que a política se baseia em valores feministas que comumente sofrem resistências pela sociedade. Neste sentido, espera-se que, quando diretrizes de gestão estiverem em consonância com os valores coletivos da instituição, elas venham a ser implementadas. Por outro lado, se essas diretrizes estiverem descoladas da realidade da instituição, a expectativa é que os trabalhadores de nível de rua busquem soluções alternativas que sejam mais compatíveis com os seus próprios valores já que as decisões no nível de rua são orientadas menos por regras e treinamentos e mais por crenças e normas (MAYNARD-MOODY; MUSHENO, 2003).

Figura 1 - Burocrata de nível de rua como variável dependente

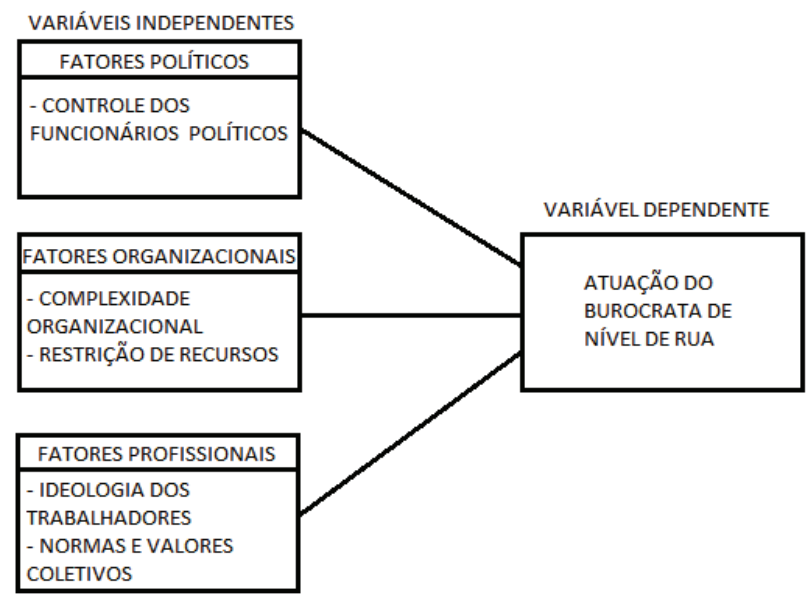

Fonte: elaboração própria. 
Observamos, portanto, alguns fatores que podem incidir na atuação dos burocratas de nível de rua. Mas é importante negritar, a partir da observação dos diferentes estudos citados ao longo desta seção, que a atuação discricionária dos burocratas de nível de rua pode estar influenciada pela atuação de diferentes fatores de forma conjunta. Ou seja, para entender a atuação destes trabalhadores é fundamental a observação e análise de diversas forças sobre o sistema de implementação.

\section{O Burocrata de nível de rua como variável independente}

A importância de analisar o comportamento dos burocratas de nível de rua está intimamente relacionada com os resultados impressos na política que a atuação desses trabalhadores pode gerar. Como afirmam Meyers e Vorsanger (2010), o grau de controle e limitação das ações discricionárias dos trabalhadores de linha de frente deve ser analisado quando houver expectativas de que isto repercuta nos resultados políticos esperados. Esses resultados esperados podem ser entendidos como variáveis dependentes que sofrem consequências da variável independente "atuação da buro-

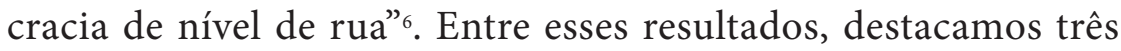
levantados pela literatura: a governança democrática, o tratamento dado à cidadania e o sucesso da política pública.

A governança democrática é a capacidade de atuação coordenada e de forma transparente entre diferentes atores que tem como objetivo colocar em prática ações, gerando resultados políticos (BEVIR, 2010). Estudos apontam uma relação negativa entre a atuação discricionária dos burocratas de nível de rua e a governança democrática a nível local (LIPSKY, 1980). Isso se deve porque os trabalhadores de ponta podem ter um potencial de enfraquecer os

6 Não estamos apresentando aqui um modelo de análise para cada uma dessas variáveis dependentes. Estamos abordando uma possível forma de relação entre a atuação dos burocratas de nível de rua, como variável independente, e cada uma das três variáveis dependentes apresentadas. Seguramente, o comportamento da variável "atuação do burocrata de nível de rua" não será suficiente para explicar as variáveis dependentes elencadas aqui. Porém, é fundamental saber que esta relação existe e que esta é uma variável que deve ser tomada em conta para analisar os diferentes resultados políticos valorizados. 
objetivos dos funcionários eleitos. À medida que os funcionários eleitos não possuem controle total das decisões e ações desses burocratas, debilitam-se os mecanismos de accountability e, consequentemente, são enfraquecidos os mecanismos de controle e avaliação destas políticas públicas (HUPE; HILL, 2007).

Por outro lado, há quem defenda que o exercício da discricionariedade na atuação laboral do burocrata de nível de rua pode, na verdade, contribuir para o incremento da governança democrática. A atuação discricionária destes trabalhadores pode proporcionar o preenchimento de lacunas entre cidadãos e funcionários eleitos, atuando como mecanismo de equilíbrio em relação ao exercício do poder dos legisladores que, via de regra, mantêm-se muito distanciados da cidadania, que é quem se vê impactada pelo resultado das decisões políticas por meio das políticas públicas (MEYERS; VORSANGER, 2010). Desta forma, os trabalhadores da ponta podem funcionar como ponte entre os políticos eleitos e a cidadania, transformando demandas dos usuários em mudanças práticas nas políticas formuladas pelos funcionários eleitos. Assim, cria-se oportunidade de que os indivíduos afetados pela política influenciem, de certa forma, na sua execução (FERMAN, 1990). Esse ciclo virtuoso pode aumentar a legitimidade e o alcance das ações do Estado.

A segunda variável dependente que pode sofrer consequências com a variação do comportamento da variável "atuação dos burocratas de nível de rua" é o tratamento dado à cidadania. Meyers e Vorsanger (2010, p. 257) afirmam que há implicação da discrição no nível de rua para os indivíduos afetados por suas ações. Em estudos como o de Bichir (2010), que apresenta a influência dos profissionais de ponta no processo de escolha das famílias potencialmente beneficiárias do programa Bolsa Família, observa-se como a atuação do burocrata de nível de rua pode incidir no tratamento aos beneficiários. Assim, podemos identificar dois possíveis comportamentos para esta variável quanto ao tratamento dado à cidadania. Por um lado, é possível que os trabalhadores da ponta aproveitem a possibilidade de uma atuação discricionária para 
gerar benefícios aos cidadãos com os quais interagem (MAYNARD-MOODY; MUSHENO, 2003). Mas, por outro lado, podemos observar a relação contrária. Estes burocratas podem fazer uso de suas prerrogativas de funcionário para limitar o acesso a benefícios, introduzindo seus próprios preconceitos como parâmetro para a distribuição (KEISER; SOSS, 1998).

Pode-se afirmar que os burocratas de nível de rua, que atuam mais próximos dos usuários, podem ter mais capacidade para considerar circunstâncias peculiares e individuais no momento de oferecer o serviço, beneficiando, assim, de forma eficaz e eficiente, os cidadãos mais necessitados de assistência naquele momento específico. A isso podemos chamar de "discriminação positiva" (GOODSELL, 1981). No outro extremo, é igualmente possível que o exercício da discricionariedade durante a atuação do burocrata de nível de rua dê a esses trabalhadores a capacidade de alocar recursos de forma indevida e para favorecimento próprio ou de pessoas escolhidas por ele, por meio de relações clientelares ${ }^{7}$. Isso poderia gerar impedimento do acesso de usuários a serviços que eles teriam direito (KEISER; SOSS, 1998; LIPSKY, 1980). Portanto, uma atuação do trabalhador da ponta de forma clientelar poderia prejudicar o cidadão na medida em que impossibilita o acesso deste a serviços públicos que deveriam ser garantidos.

A terceira, e última, variável apresentada neste modelo e que sofreria a influência da atuação dos burocratas de nível de rua relaciona-se com o êxito dos objetivos das políticas públicas. Esta variável pode ser chamada de "sucesso das políticas". Autores afirmam que a capacidade dos trabalhadores da ponta de adaptar a política às realidades locais pode incidir na sensibilidade e na efetividade das políticas públicas por meio da experiência prática desses burocratas (MEYERS; VORSANGER, 2010; PRESSMAN; WILDAVSKY, 1973). Porém, essa influência dos trabalhadores

7 Entendemos por"relações clientelares"aquelas estabelecidas sobre a base do clientelismo. De acordo com Nunes (1997), o clientelismo consiste na assimetria de poder que se manifesta em situações de solidariedade mútua, exploração e coerção potencial por relações voluntárias e obrigações mútuas. No clientelismo há uma deturpação na relação entre Estado e sociedade. 
da ponta pode introduzir nós de incerteza na implementação da política. Como o sucesso das políticas públicas depende da cooperação entre formuladores, implementadores e usuários, a presença de nós de incerteza dificultam essa relação de cooperação e, consequentemente, podem impactar negativamente no resultado da política (MEYERS; VORSANGER, 2010). Isso se deve à possível diferença nos interesses relativos à política por partes destes grupos. Por outro lado, se os implementadores realmente desejam fazer com que as políticas sejam efetivamente implementadas, isso pode acontecer com custos menos elevados devido à disposição de aprendizado dos burocratas de nível de rua (HILL, 2003).

Figura 2 - Burocrata de nível de rua como variável independente

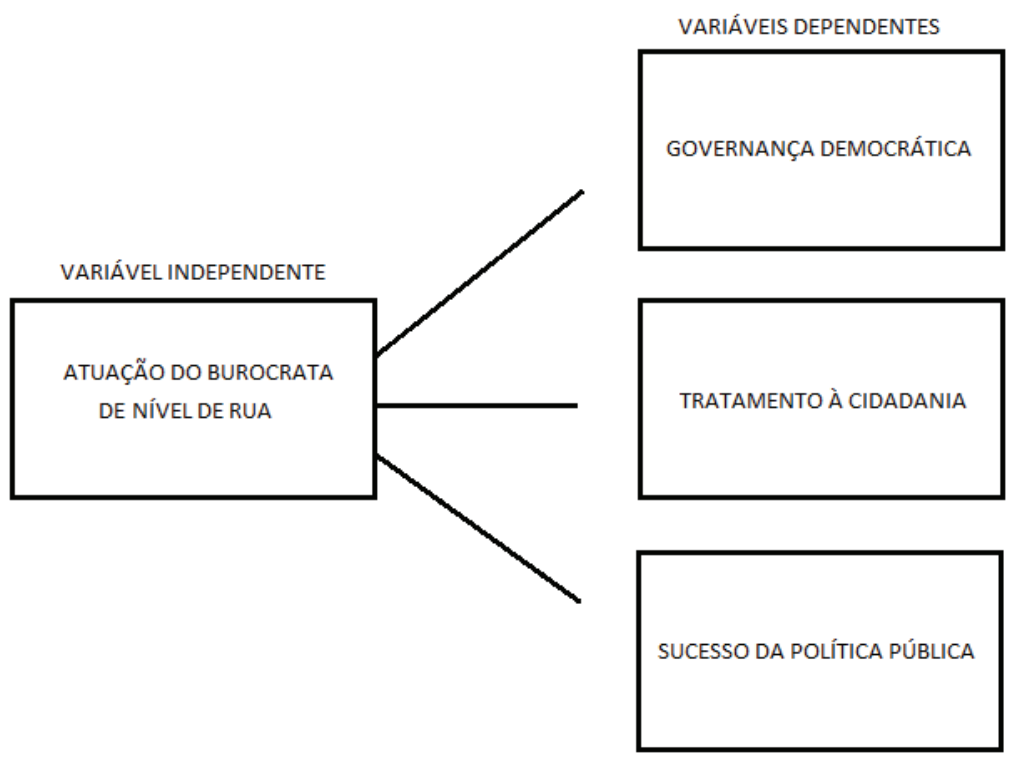

Fonte: elaboração própria.

Portanto, a importância de se debater a atuação dos trabalhadores da ponta tem ligação direta com os impactos desta atuação nos resultados políticos gerados em termos de políticas públicas. 
Tomar a variável "atuação dos burocratas de nível de rua" como fator explicativo de outros fenômenos intrínsecos à implementação de políticas é assumir que estes atores possuem um papel importante, ainda que por vezes negligenciado, na configuração da implementação e alcance de objetivos e impactos das políticas.

\section{O contexto como variável interveniente}

Para além de tomar a variável "atuação da burocracia de nível de rua" como dependente ou independente na análise de implementação das políticas públicas, é importante considerar uma possível variável interveniente ${ }^{8}$ que incide na leitura e interpretação do labor destes burocratas: o contexto.

Alterações no ambiente em que se implementa uma política pública são esperadas e, em alguma medida, imprevisíveis (WITTROCK; DELEON, 1986). Por esse motivo, a contextualização das análises envolvendo a atuação dos burocratas de nível de rua é fundamental para calibrar as conclusões apresentadas pelos analistas e, assim, evitar a atribuição de créditos indevidos a estes trabalhadores, por um lado, e responsabilidades equivocadas no resultado de políticas, por outro lado.

As características institucionais de cada cenário político podem determinar diferentes leituras para a atuação dos burocratas da ponta. Os contextos de implementação podem variar de acordo com os países e seus sistemas políticos, desde uma perspectiva institucionalista. Por exemplo, analisar o trabalho da burocracia em um sistema federado traz elementos importantes próprios do funcionamento deste tipo de arranjo político que possibilitam fazer uma leitura particular sobre a atuação dos trabalhadores de nível de rua. Além disso, diferentes sistemas políticos produzem respostas

8 Fator ou propriedade que teoricamente afeta o fenômeno observado, mas não pode ser manipulado ou mensurado pelo pesquisador (King; Keohane;Verba, 1994). Variáveis intervenientes não podem ser consideradas como independentes na medida em que não podem ser manipuladas pelo pesquisador. No entanto, podem influenciar os valores assumidos pelas variáveis dependentes. Essas variáveis podem prejudicar a relação causa-efeito entre variáveis independentes e dependentes, influenciando o resultado da pesquisa sem que o pesquisador consiga isolá-las para análise ou suprimir tais fatores intervenientes na pesquisa (Lakatos; Marconi, 2003). 
diferentes às demandas sociais geradas, considerando que os referidos sistemas possuem concepções próprias sobre cidadania, solidariedade e confiança (MØLLER; STENSÖTA, 2019).

Arretche (2001) afirma que a diversidade de contextos de implementação pode produzir resultados completamente diferentes a partir de uma mesma política pública devido à interação entre a política e a realidade local. Pelo mesmo motivo, análises sobre os trabalhadores de ponta devem se preocupar em consideração o contexto em que sucede a implementação (MEYERS; VORSANGER, 2010).

Segundo Lowi (1972), o tipo de política pública - policy - determina o jogo político - politics. Assim, a depender do tipo de política pública que está sendo disputada na arena política, a estrutura dos conflitos, disputas e equilíbrios políticos irão modificar-se. Neste sentido, podemos afirmar que os contextos de implementação também podem variar de acordo com o tipo de política. Comparando a atuação dos burocratas de nível de rua em políticas que envolvem problemas sociais mais complexos com políticas propostas para enfrentar questões menos complexas, deparamo-nos com diferentes análises. Nesta mesma lógica, os recursos e o público-alvo intrínseco a cada tipo de política também compõem o contexto a ser levado em consideração para análises de implementação vinculadas à atuação dos burocratas da ponta.

Algumas das contradições encontradas nos resultados de estudos que utilizam a atuação dos burocratas de nível de rua como variável dependente ou independente se deve, em alguns casos, à falta de contextualização da implementação por parte do pesquisador. Dessa forma, a deficiência em contextualizar os cenários de implementação tem prejudicado análises sérias e sistemáticas da burocracia de nível de rua.

Portanto, é fundamental considerar os contextos de implementação para a realização de uma correta leitura sobre a atuação dos burocratas de nível de rua, com esta categoria exercendo o papel de variável dependente ou independente conforme já apresentado. Deixar de lado o processo de contextualização nas análises realizadas 
pode levar a uma leitura equivocada da atuação dos burocratas de nível de rua e, ainda, atribuir crédito indevido ou culpabilizar de forma errônea estes atores pelo resultado de políticas.

\section{Considerações finais}

Durante as últimas décadas, os estudos sobre burocracia de nível de rua avançaram consideravelmente. Essa literatura tem analisado a discricionariedade desses atores, os fatores que os influenciam e como eles afetam os resultados das políticas e o acesso do cidadão a bens e serviços públicos.

Analisar a implementação possibilita visualizar, de forma estruturada, os obstáculos e as falhas que costumam surgir nessa fase do processo de políticas públicas. Além disso, possibilita perceber falhas anteriores à tomada de decisão para detectar problemas mal formulados, objetivos mal desenhados ou resultados esperados desproporcionados. Nesse sentido, na medida em que é responsável por distribuir benefícios e sanções, a burocracia de nível de rua protagoniza controvérsias políticas relevantes no que diz respeito à prestação de serviços públicos. Tais controvérsias estão relacionadas à distribuição dos benefícios entre os cidadãos, a proximidade que estabelecem com eles comprometendo o ideal de impessoalidade que se espera das burocracias, a estrutura institucional e programática na qual sua atuação se insere, as suas condições de trabalho e a abrangência dos objetivos das políticas públicas. Diante de tais questões, os burocratas de nível de rua deparam com uma série de brechas nessas estruturas que lhes possibilita agir com substancial grau de discricionariedade.

Deste ponto decorre a discussão sobre legitimidade da atuação discricionária dos burocratas, na medida em que esses atores não são agentes eleitos pelos cidadãos para moldar as políticas públicas. Mas, por outro lado, as interações que estabelecem os colocam em situação de relativo privilégio para intervir nas políticas de forma a aperfeiçoar questões que não estavam previstas em sua formulação e assim conformar a política pública e aproximá-la das necessidades dos usuários. Verifica-se, portanto, que esse 
instigante debate evidencia a centralidade da discricionariedade dos burocratas de nível de rua e apresenta as controvérsias que existem em torno desta categoria analítica.

Diante disso, incitou-se neste artigo duas propostas diferentes para analisar a atuação da burocracia de nível de rua: a primeira, considerando esta uma variável dependente, influenciada por outros fatores; e a segunda, considerando-a uma variável independente, como fator influenciador de outros processos políticos. Ao pensar a atuação do burocrata de nível de rua enquanto variável dependente, mobilizam-se fatores políticos, fatores organizacionais e fatores profissionais para explicá-la. Já quando se toma a atuação do burocrata de nível de rua como variável independente, argumenta-se, com base na literatura, que ela pode influenciar na governança democrática, no tratamento dado à cidadania e no sucesso das políticas públicas. Para além dessas possibilidades de análise, destaca-se a importância de se considerar o contexto enquanto variável interveniente capaz de influir no fenômeno analisado. Assim sendo, a contextualização das análises envolvendo a atuação dos burocratas de nível de rua é fundamental para calibrar as conclusões apresentadas pelos analistas.

Portanto, o aumento do número de estudos sobre a burocracia de nível de rua apresenta cenários diferentes, e até mesmo contraditórios, sobre a atuação destes trabalhadores no processo de implementação de políticas públicas. Estas contradições, além de reforçarem a necessidade de aprofundar, de forma sistemática e metodologicamente cuidadosa, os estudos sobre a burocracia de nível de rua, evidenciam a centralidade da atuação desses trabalhadores.

\section{Referências}

ALESSIO, Maria Fernanda; AMBROZIO, Lucas. A composição da alta burocracia no Brasil e no Chile à luz das dimensões da legitimidade e do desempenho. Revista do Serviço Público, v. 67, n. 3, p. 319-350, 2016. 
ARRETCHE, Marta. Uma contribuição para fazermos avaliações menos ingênuas. In: MOREIRA, M. C. R.; CARVALHO, M. C. B. de (org). Tendências e perspectivas na avaliação de políticas e programas sociais. São Paulo: IEE/PUC SP, 2001.

AUYERO, Javier. Patients of the state: the politics of waiting in Argentina. Durham, NC; London: Duke University Press, 2012.

BARDACH, Eugene. The implementation game: what happens after a bill becomes a law. Massachusetts: Massachusetts Institute of Technology, 1977.

BARRETT, Susan M. Implementation studies: time for a revival? Personal reflections on 20 years of implementation studies. Public Administration, v. 82, n. 2, p. 249-262, 2004.

BERGEN, Ann; WHILE, Alison. 'Implementation deficit' and 'street-level bureaucracy': policy, practice and change in the development of community nursing issues. Health and Social Care in the Community, v. 13, n. 1, p. 1-10, 2004.

BERMAN, P. The study of macro and micro implementation. Public Policy, v. 26, n. 2, p. 157-184, 1978.

BERK, Gerald.; GALVAN, Dennis. C.; HATTAM, Victoria. (eds.). Political creativity: reconfiguring institutional order and change. Philadelphia: University of Pennsylvania Press, 2013.

BEVIR, Mark. Democratic Governance. Princeton: Princeton University, 2010.

BICHIR, Renata. O Bolsa Família na berlinda? Os desafios atuais dos programas de transferência de renda. Novos Estudos Cebrap, n. 87, p. 115-129, 2010.

BONELLI, F. et al. A atuação dos burocratas de nível de rua na implementação de políticas públicas no Brasil: uma proposta de análise expandida. Cadernos EBAPE.BR, v. 17, edição especial, p. 800-816, 2019.

CORDEIRO, Natália. Profissionais no olho do furacão: o papel das educadoras sociais na implementação da política de abrigamento para mulheres ameaçadas de morte em Pernambuco. Dissertação (Mestrado em Ciência Política). Recife: Universidade Federal de Pernambuco, 2018. 
DELEON, Peter. The missing link revisited: contemporary implementation research. Policy Studies Review, v. 16, n. 3/4, p. 311-338, 1999.

ELMORE, Richard. Forward and backward mapping: reversible logic in the analysis of public policy. In: HAND, K.; TOONEN, T. A. J. (ed). Policy implementation in Federal and Unitary Systems. Dordrecht: Martinus Nijhoff, 1985, p. 71-96.

ELMORE, Richard. Backward mapping: implementation research and policy decisions. Political Science Quarterly, v. 94, n. 4, p. 601-616, 1979.

FERREIRA, Vicente da Rocha Soares; MEDEIROS, Janann Joslin. Fatores que moldam o comportamento dos burocratas de nível de rua no processo de implementação de políticas públicas. Cadernos EBAPE.BR, v. 14, n. 3, p. 776-793, 2016.

FERMAN, Barbara. When failure is success: implementation and madisonian government. In: PALUMBO, Dennis J.; CALISTA, Donald J. (ed). Implementation and the policy process: opening up the black box. Westport: Greenwood Press, 1990, p. 35-50.

GOGGIN, Malcolm et al. Studying the dynamics of public policy implementation: a third-generation approach. In: PALUMBO, Dennis J.; CALISTA, Donald J. (ed). Implementation and the policy process: opening up the black box. Westport: Greenwood Press, 1990, p. 19-38.

GOODSELL, Charles. The new comparative administration: a proposal. International Journal of Public Administration, v. 3, n. 2, p. 143-155, 1981.

HILL, H. Understanding implementation: street-level bureaucrats' resources for reform. Journal of Public Administration Research and Theory, v. 13, n. 3, p. 265-282, 2003.

HILL, Michael; HUPE, Peter. Implementing public policy: an introduction to the study of operational governance. 3. ed. London: Sage, 2014.

HILL, Michael; HUPE, Peter. The multi-layer problem in implementation research. Public Management Review, v. 5, n. 4, p. 471-490, 2003. 
HJERN, Benny. Implementation research-the link gone missing. Journal of Public Policy, v. 2, n. 3, p. 301-308, 1982.

HUPE, Peter; EDWARDS, Arthur. The accountability of power: democracy and governance in modern times. European Political Science Review, v. 4, n. 2, p. 177-194, 2012.

HUPE, Peter; HILL, Michael. Street-level bureaucracy and public accountability. Public Administration, v. 85, n. 2, p. 279-299,2007.

KEISER, Lael. State bureaucratic discretion and the administration of social welfare programs: the case of social security disability. Journal of Public Administration Research and Theory, v. 9, n. 1, p. 87-106, 1999.

KEISER, Lael; SOSS, Joe. With good cause: bureaucratic discretion and the politics of child support enforcement. American Journal of Political Science, v. 42, n. 4, p. 1133-1156, 1998.

KING, Gary; KEOHANE, Robert O.; VERBA, Sidney. Designing social inquiry: scientific inference in qualitative research. New Jersey: Princeton University Press, 1994.

LAKATOS, Eva. Maria; MARCONI, Marina Andrade. Metodologia científica. 3. ed. São Paulo: Atlas, 1991.

LESTER et al. Public policy implementation: evolution of the field and agenda for future research. Policy Studies Review, v. 7, n. 1, p. 200-216, 1987.

LIMA, Luciana Leite; D’ASCENZI, Luciano. O papel da burocracia de nível de rua na implementação e (re)formulação da Política Nacional de Humanização dos serviços de saúde de Porto Alegre (RS). Revista de Administração Pública, v. 51, n. 1, p. 46-63, 2017.

LIMA, Luciana Leite; D’ASCENZI, Luciano. Implementação de políticas públicas: perspectivas analíticas. Revista de Sociologia e Política, v. 21, n. 48, p. 101-110, 2013.

LIPSKY, Michael. Street level bureaucracy: dilemmas of the individual in public services. Nova Iorque: Russell Sage Foundation, 1980. 
LOTTA, Gabriela Spanghero. A política pública como ela é: contribuições dos estudos sobre implementação para a análise de políticas públicas. In: LOTTA, Gabriela Spanghero (org.). Teoria e análises sobre implantação de políticas públicas no Brasil. Brasília: Enap, 2019, p. 11-38.

LOTTA, Gabriela Spanghero. O papel das burocracias do nível da rua na implementação de políticas públicas: entre o controle e a discricionariedade. In: FARIA, C. A. P. (org.). Implementação de políticas públicas: teoria e prática, Belo Horizonte: Editora PUC Minas, 2012, p. 20-49.

LOTTA, Gabriela Spanghero. Implementação de políticas públicas: o impacto dos fatores relacionais e organizacionais sobre a atuação dos Burocratas de Nível de Rua no Programa Saúde da Família. Tese (Doutorado em Ciência Política). São Paulo: Universidade de São Paulo, 2010.

LOTTA, Gabriela Spanghero; PIRES, Roberto Rocha Coelho; OLIVEIRA, Vanessa Elias. Burocracia e políticas públicas no Brasil: interseções analíticas. Brasília: Ipea, 2018.

LOTTA, Gabriela Spanghero; PIRES, Roberto Rocha Coelho; OLIVEIRA, Vanessa Elias. Burocratas de médio escalão: novos olhares sobre velhos atores da produção de políticas públicas. Revista do Serviço Público, v. 65, n. 4, p. 463-492, 2014.

LOTTA, Gabriela; SANTIAGO, Ariadne. Autonomia e discricionariedade: matizando conceitos-chave para o estudo de burocracia. BIB, v. 1, n. 83, p. 776-793, 2017.

LOTTA et al. Por uma agenda brasileira de estudos sobre implementação de políticas públicas. Revista do Serviço Público Brasília, v. 69, n. 4, p. 779-810, 2018.

LOWI, Theodore. Four systems of policy, politics, and choice. Public Administration Review, v. 32, n. 4, p. 298-310, 1972.

MATLAND, Richard E. Synthesizing the implementation literature: the ambiguity-conflict model of policy implementation. Journal of Public Administration Research and Theory, v. 5, n. 2, p. 145-174, 1995. 
MAY, Peter; WINTER, Søren. Politicians, managers, and streetlevel bureaucrats: influences on policy implementation. Journal of Public Administration Research and Theory, v. 19, n. 3, p. 453-476, 2007.

MAYNARD-MOODY, Steven; MUSHENO, Michael. Playing the rules: discretion in social and policy context. In: HUPE, P.; HILL, M.; BUFFAT, A. Understanding street-level bureaucracy. Chicago: Policy Press, 2015, p. 169-186.

MAYNARD-MOODY, Steven; MUSHENO, Michael. Social equities and inequities in practice: street-level workers as agents and pragmatists. Public Administration Review, v. 72, n. 1, p. 16-23, 2012.

MAYNARD-MOODY, Steven; MUSHENO, Michael. Cops, teachers, counselors: narratives of street-level judgment. Ann Arbor: University of Michigan Press, 2003.

MAYNARD-MOODY, Steven; MUSHENO, Michael. State agent or citizen agent: two narratives of discretion. Journal of Public Administration Research and Theory, v. 10, n. 2, p. 329-358, 2000.

MEIER, Kenneth J.; O'TOOLE, Laurence J. Bureaucracy in a democratic state: a governance perspective. Baltimore: The John Hopkins University Press, 2006.

MENY, Y.; THOENIG, J. C. Las políticas públicas. Barcelona: Ariel, 1992.

MEYERS, Marcia K.; VORSANGER, S. Burocratas de nível de rua e a implementação de políticas públicas. In: PETERS, G.; PIERRE, J. (org.). Administração pública: coletânea. São Paulo/Brasília: Unesp/Enap, 2010, p. 249-270.

MØLLER, M.; STENSOTA, H. Welfare state regimes and caseworkers' problem explanation. Administration \& Society, v. 51, n. 9, p. 1-30, 2019.

MOON, Myung-Jae; INGRAHAM, Patricia. Shaping administrative reforms and governance: an examination of the political nexus triad in three Asian countries. Governance, v. 11, n. 1, p. 77-100, 1998. 
NUNES, Edson. A gramática política do Brasil: clientelismo e insulamento burocrático. Rio de Janeiro: Zahar, 1997.

OLIVEIRA, Antonio. Burocratas da linha de frente: executores e fazedores das políticas públicas. Revista de Administração Pública, v. 6, n. 46, p. 1551-1573, 2012.

OLIVIERI, Cecília. Os controles políticos da burocracia. Revista de Administração Pública, v. 45, n. 5, p. 1395-1424, 2011.

PIRES, Roberto Rocha C. Implementando desigualdades: reprodução de desigualdades na implementação de políticas públicas. Rio de Janeiro: Ipea, 2019.

PRESSMAN, J.; WILDAVSKY, A. Implementation: how great expectations in Washington are dashed in Oakland or, why it's amazing that federal programs work at all, this being a saga of the Economic Development Administration as told by two sympathetic observers who seek to build morals on a foundation of ruined hopes. Berkeley: University of California Press, 1973.

SABATIER, Paul. An advocacy coalition framework for policy change and the role of policy-oriented learning therein. Policy Sciences, v. 21, n. 2/3, p. 129-168, 1988.

SABATIER, Paul. Top-down and bottom-up approaches to implementation research: a critical analysis and suggested synthesis. Journal of Public Policy, v. 6, n. 1, p. 21-48, 1986.

SAETREN, H. Implementing the third generation research paradigm in policy implementation research: an empirical assessment. Public Policy and Administration, v. 29, n. 2, p. 84-105, 2014. SECCHI, Leonardo. Políticas públicas: conceitos, esquemas de análise, casos práticos. São Paulo: Cengage Learning, 2010.

SIMON, William. Legality, bureaucracy, and class in the welfare system. The Yale Law Journal, n. 92, p. 1198-1983, 1983.

SOUZA, Celina. Políticas públicas: uma revisão de literatura.

Revista Sociologias, v. 8, n. 16, p. 20-45, 2006.

WEBER, Max. The theory of social and economic organizations.

New York: Free Press, 1947.

WILSON, Woodrow. The study of administration. Political Science Quarterly, v. 2, n. 2, p. 197-222, 1887. 
WINTER, Søren. Perspectivas de implementação: status e reconsideração. In: PETERS, G.; PIERRE, J. (org.). Administração pública: coletânea. São Paulo/ Brasília: Unesp/ Enap, 2010, p. 209-228.

WITTROCK, B.; DELEON, P. Policy as a moving target: a call for conceptual realism. Policy Studies Review, v. 6, n.1, p. 44-60, 1986.

\section{Resumo}

Este artigo tem como objetivo apresentar estratégias teóricometodológicas para o estudo da burocracia em nível de rua. A partir de uma revisão de literatura são apresentadas as diferentes gerações de estudos sobre implementação, o papel da burocracia como ator no processo de implementação, além do lugar dos burocratas de nível de rua na implementação de políticas e a discricionariedade desses burocratas enquanto categoria de análise. Por fim, são propostas estratégias de pesquisa para a análise do papel dos burocratas de nível de rua na implementação das políticas.

Palavras-chave: implementação de políticas públicas, burocracia de nível de rua, discricionariedade, estratégias teórico-metodológicas.

\section{Abstract}

The purpose of this paper is to present theoretical-methodological strategies for the study of street-level bureaucracy. Starting with a literature review, we present the different generations of research on public policy implementation, the role of bureaucracy as an actor in the implementation process, the place of street-level bureaucrats in policy implementation, and bureaucratic discretion as a category of analysis. Finally, we propose a set of theoretical-methodological research strategies for analyzing the role of street-level bureaucrats in policy implementation.

Keywords: implementation of public policies, street-level bureaucracy, discretion, theoretical-methodological strategies.

Recebido em 21 de fevereiro de 2019

Aprovado em 02 de junho de 2020 